\title{
Protein Kinase Interaction
}

National Cancer Institute

\section{Source}

National Cancer Institute. Protein Kinase Interaction. NCI Thesaurus. Code C40533.

Protein Kinase Interaction involves temporary non-covalent binding through

intermolecular physical forces of attraction and spatial complementarity with members

of a family of enzymes that catalyze the conversion of ATP and a protein to ADP and a phosphoprotein. 